Jurnal SEOI - Fakultas Teknik Universitas Sahid Jakarta

Vol 2 edisi 2 tahun 2020

\title{
KAJIAN PEMANFAATAN LAHAN DALAM MEMAKSIMALKAN SARANA PENGOLAHAN SAMPAH ORGANIK DI KELURAHAN KEBON PISANG KOTA BANDUNG
}

\author{
STUDY OF LAND UTILIZATION IN MAXIMIZING ORGANIC WASTE \\ TREATMENT FACILITIES IN KEBON PISANG KELURH, BANDUNG CITY
}

\author{
Yuliaty Heliana P1, Muhamad Dzaki Maulana ${ }^{2}$ \\ 1,2 Jurusan Teknik Lingkungan, Fakultas Teknik, Perencanaan dan Arsitektur \\ Universitas Winaya Mukti, Email : yuliatyheliana@gmail.com
}

\begin{abstract}
ABSTRAK
Pemerintah Kota Bandung memiliki target pengurangan sampah hingga tahun 2025 sebesar 30\%, pemerintah Kota Bandung mencanangkan program Kawasan Bebas Sampah (KBS) dalam upaya pengurangan sampah. RW 7 Kelurahan Kebon Pisang merupakan salah satu wilayah yang sudah termasuk Kawasan Bebas Sampah sejak tahun 2015. Penelitian ini bertujuan (1) untuk mengindetifikasi mengenai efisiensi pengolahan sampah organik di RW 7 Kelurahan Kebon Pisang (2) untuk Mengetahui sarana pengolahan sampah yang terdapat di RW 7 Kelurahan Kebon Pisang, yang bertujuan untuk menentukan alternatif upaya pemanfatan lahan (3) untuk menghitung kebutuhan sarana pengolahan sampah organik rumah tangga untuk mengetahui kebutuhan sarana yang akan diimplementasikan dan menyesuaikan dengan ketersediaan lahan (4) untuk menentukan alternatif terpilih yang akan diimplementasikan sebagai upaya optimalisasi sarana pengolahan sampah organik rumah tangga terpilih berdasarkan kriteria penentuan. Berdasarkan hasil penelitian timbulan sampah organik yang tereduksi untuk saat ini hanya mencapai 3,15\% hasil ini masih jauh dari target pemerintah Kota Bandung, maka dari itu dilakukan perhitungan dan analisa untuk kebutuhan sarana yang dibutuhkan dan menyesuaikan dengan ketersediaan lahan, lalu mendapatkan hasil untuk alternatif terpilih yang akan diimplementasikan yaitu sarana drum komposter (single treatment unit).
\end{abstract}

Kata kunci : sampah organik, timbulan sampah, lahan,

\section{ABSTRACT}

The Bandung City Government has a target of reducing waste by 2025 by 30\%, the Bandung City government launched the Waste Free Zone $(K B S)$ program in an effort to reduce waste. RW 7 Kebon Pisang Village is one of the areas that has been included as a Waste Free Zone since 2015. This study aims (1) to identify the efficiency of organic waste processing in RW 7 Kebon Pisang Village (2) to determine the waste processing facilities in RW 7 Kelurahan Kebon Pisang, which aims to determine alternative land use efforts (3) to calculate the need for household organic waste processing facilities to determine the need for facilities to be implemented and adjust to the availability of land (4) to determine alternatives to be implemented as an effort to optimize facilities household waste treatment is selected based on the criteria. Based on the research results, the reduced organic waste generation currently only reaches $3.15 \%$. This result is from the Bandung City government target, therefore calculations and analyzes are carried out for the needs of the facilities needed and adjust to the availability of land, and get selected results that will be implemented. namely the means of a composter drum (single treatment unit).

Keywords ; organic waste, waste generation, land 
Jurnal SEOI - Fakultas Teknik Universitas Sahid Jakarta

Vol 2 edisi 2 tahun 2020

\section{Pendahuluan}

\section{Latar Belakang}

Berdasarkan Undang-Undang No.18 tahun 2008 sampah merupakan sisa kegiatan seharihari manusia dan/atau proses alam yang berbentuk padat. Sampah merupakan limbah padat yang memerlukan proses pengolahan agar tidak berdampak buruk bagi sekitarnya. Pengelolaan sampah terdapat dua aspek, yaitu pengurangan dan penanganan sampah. Berdasarkan Pasal 12 Ayat 1, menjelaskan bahwa setiap orang wajib mengurangi dan menangani sampah rumah tangga dengan cara yang berwawasan lingkungan. Kegiatan pengolahan sampah dapat berupa pemadatan, pengomposan, daur ulang materi dan daur ulang energi.

Pemerintah Kota Bandung merupakan salah satu yang sangat menerapkan pengurangan sampah secara bertahap dengan menetapkan target pengurangan dalam jangka waktu tertentu. Pemerintah Kota Bandung dalam Rencana Pembangunan Jangka Menengah Daerah (RPJMD) Tahun 2014-2018 menyebutkan bahwa target pengurangan sampah Kota Bandung hingga tahun 2025 adalah 30\%. Pada tahun 2014, pemerintah Kota Bandung mencanangkan program Kawasan Bebas Sampah atau KBS, sebagai perwujudan untuk menunjang tercapainya penerapan pengelolaan sampah yang sesuai dengan Undang-Undang Republik Indonesia Nomor 18 Tahun 2008 dan Peraturan Pemerintah Republik Indonesia Nomor 81 Tahun 2012.

Kelurahan Kebon Pisang merupakan salah satu kelurahan dari 8 kelurahan di Kota Bandung yang telah menjadi KBS. Kelurahan Kebon Pisang memiliki jumlah penduduk 12.146 jiwa yang tersebar pada 12 rukun warga (RW). Luas wilayah Kelurahan Kebon Pisang ini adalah 65 hektar dengan tingkat kepadatan penduduk sebesar 186,86 jiwa/hektar. Kelurahan Kebon Pisang adalah satu dari 8 (delapan) KBS di Kota Bandung yang telah melakukan pemilahan dari sumber dan pengolahan sampah skala kawasan. RW 7 merupakan RW KBS di Kelurahan Kebon Pisang, dengan jumlah penduduk sebanyak 1.856 jiwa. RW 7 Kelurahan Kebon Pisang memiliki lahan pengolahan anorganik berupa bank sampah dan belum mengoptimalkan pengolahan sampah organik.

Pada penelitian sebelumnya yang dilakukan di Kelurahan Kebon Pisang oleh Djulianti (2019), diperoleh tingkat pengurangan sampah dengan pengolahan sampah organik skala kawasan di RW 7 Kelurahan Kebon Pisang baru mencapai 7,34\%, sedangkan total komposisi sampah organik adalah 53,69\% dari 100\% keseluruhan sampah. Sebagai salah satu dari empat kegiatan utama KBS, pengolahan sampah organik di kawasan perlu ditingkatkan dengan cara mengoptimalkan penggunaan sarana pengolahan sampah organik dan pemanfaatan lahan pengolahan sampah eksisting.

Upaya optimalisasi sarana pengolahan sampah organik rumah tangga dan pemanfaatan lahan pengolahan di RW 7 Kelurahan Kebon Pisang ini akan merencanakan alternatif-alternatif guna mengoptimalkan sarana pengolahan sampah dengan memperhatikan jumlah sarana pengolahan, kapasitas pengolahan, kemudahan manajemen sarana pengolahan sampah organik rumah tangga, dan sarana paling ekonomis, sehingga dapat diimplementasikan di kawasan guna meningkatkan target pengurangan sampah.

\section{Maksud dan Tujuan}

1. Mengindetifikasi mengenai efisiensi pengolahan sampah organik eksisting di RW 7 Kelurahan Kebon Pisang

2. Mengetahui sarana pengolahan sampah eksisting yang terdapat di RW 7 Kelurahan Kebon Pisang, yang bertujuan untuk menentukan alternatif upaya pemanfatan lahan

3. Meninjau luas lahan total dan luas lahan efektif pengolahan eksisting serta pemanfaatannya 
Jurnal SEOI - Fakultas Teknik Universitas Sahid Jakarta

Vol 2 edisi 2 tahun 2020

4. Menghitung kebutuhan sarana pengolahan sampah organik rumah tangga untuk mengetahui kebutuhan sarana yang akan diimplementasikan dan menyesuaikan dengan ketersediaan lahan

5. Memproyeksikan jumlah penduduk dan timbulan sampah Kelurahan Kebon Pisang RW 7 untuk merencanakan sarana pengolahan sampah sampai tahun 2025

6. Menentukan alternatif-alternatif pemanfaatan lahan untuk sarana pengolahan sampah

7. Menentukan alternatif terpilih yang akan diimplementasikan sebagai upaya optimalisasi sarana pengolahan sampah organik rumah tangga terpilih berdasarkan kriteria penentuan.

\section{Metodologi Penelitian}

Dimulai dari persiapan lalu mengidentiffikasi masalah, dilanjutkan mencari studi literatur dan melakukan pengumpulan data primer dan sekunder yang dibutuhkan untuk proses analisa. Sebelum dilakukan proses pengomposan, bahan baku sampah organik diidentifikasi karakteristiknya. Identifikasi karakteristik bahan kompos yang akan digunakan meliputi kandungan kadar air, kadar volatil, C-organik, $\mathrm{N}$ total, rasio $\mathrm{C} / \mathrm{N}$. identifikasi karakteristik dilakukan melalui uji pendahuluan di laboratorium. Nanti hasilnya akan ditinjau untuk menghitung dan merekomendasikan alternatif-alternatif yang akan diimplementasikan agar dapat memaksimalkan lahan dan mereduksi sampah.

Untuk menentukan alternatif terpilih ditenntukan dari berbagai aspek, yaitu:

1. Meningkatkan persentase reduksi sampah hingga mencapai $30 \%$ pada tahun 2025.

2. Memilih sarana pengolahan yang paling memungkinkan untuk diimplementasikan di lahan pengolahan eksisting.

3. Memilih sarana pengolahan yang paling mudah dioperasikan dan mudah dirawat.

4. Memilih sarana pengolahan yang membutuhkan biaya perawatan paling murah.

\section{Hasil dan Pembahasan}

\section{Analisa Timbulan Sampah Organik}

Timbulan sampah organik RW 7 Kelurahan Kebon Pisang adalah sebesar 429,7 kg/hari. Timbulan ini dihitung dengan perhitungan sebagai berikut:

$=$ total timbulan sampah $\mathrm{x}$ persentase sampah organik

$=835,2 \mathrm{~kg} / \mathrm{hari} \times 51,45 \%$

$=429,7 \mathrm{~kg} / \mathrm{hari}$

\section{Kondisi Eksisting Pengolahan Sampah Berdasarkan Penelitian Sebelumnya Sarana}

Berdasarkan penelitian sebelumnya, sarana bata terawang digunakan untuk mengolah sampah organik berupa sisa dapur dan sisa makanan seperti nasi, sayuran, dan buah-buahan. Terdapat dua unit sarana dengan kapasitas dan dimensi yang berbeda. Kedua unit ini berfungsi dengan baik dan akan menghasilkan kompos sebagai produk akhirnya. Sarana drum komposter sebanyak empat buah, digunakan untuk mengolah sampah organik sisa makanan dengan produk akhir pupuk cair dan juga kompos. Sarana biodigester pada kondisi eksisting merupakan biodigester tipe terapung yang produk akhirnya merupakan biogas dan kompos cair. Namun, berdasarkan hasil wawancara dengan operator sarana pengolahan, karena minimnya perawatan dan kurangnya minat masyarakat pada biodigester, sarana tersebut kini menjadi tidak berfungsi. 
Jurnal SEOI - Fakultas Teknik Universitas Sahid Jakarta

Vol 2 edisi 2 tahun 2020

Tabel 1. Kondisi Eksisting Sarana Pengolahan Sampah

\begin{tabular}{cccccc}
\hline No & Jenis Sarana & Jumlah & Dimensi $(\mathbf{m})$ & Kapasitas & Kondisi \\
\hline 1 & $\begin{array}{c}\text { Bata Terawang } \\
(\mathrm{p} \times 1 \times \mathrm{t})\end{array}$ & 2 & $\bullet 0,75 \times 0,64 \times 1,23$ & $\bullet 0,59 \mathrm{~m}^{3}$ & Baik \\
2 & $\begin{array}{c}\text { Drum Komposter } \\
(\mathrm{d} \times \mathrm{t})\end{array}$ & 4 & $0,73 \times 0,57 \times 1,25$ & $\bullet 0,52 \mathrm{~m}^{3}$ & \\
3 & $\begin{array}{c}\text { Biodigester } \\
(\mathrm{p} \times 1 \times \mathrm{t})\end{array}$ & 1 & $0,75 \times 1,3$ & $0,58 \mathrm{~m}^{3}$ & Baik \\
\hline
\end{tabular}

\section{Pemanfaatan Lahan}

Hasil dari pengukuran langsung di lapangan memperoleh total luas lahan eksisting adalah sebesar 98,56 $\mathrm{m}^{2}$ dengan luas lahan efektif sebesar 39,85 $\mathrm{m}^{2}$, dengan dengan rincian 30,02 $\mathrm{m}^{2}$ untuk area pemilahan dan $9,83 \mathrm{~m}^{2}$ untuk penempatan sarana. Yang dimaksud dengan luas lahan efektif adalah luas lahan yang digunakan hanya untuk sarana pengolahan, area pemilahan, dan tempat untuk ruang gerak pekerja. Sedangkan sisa lahan yang belum efektif sebesar $58,71 \mathrm{~m}^{2}$, untuk saat ini lahan tersebut digunakan untuk tempat parkir motor dan menyimpan gerobak dorong yang digunakan untuk pengangkutan sampah.

\section{Reduksi Sampah}

Peninjauan pada kondisi eksisting, reduksi sampah organik keseluruhan oleh sarana yang ada di RW 7 Kelurahan Kebon Pisang baru mencapai 3,15\% atau sebesar 26,6 kg/hari. Jumlah ini masih sangat sedikit apabila dibandingkan dengan timbulan sampah organik harian yang mencapai 429,71 kg/hari, karena timbulan sampah yang dihasilkan dari RW 7 Kelurahan Kebon Pisang tidak diimbangi dengan sarana pengolahan sampahnya.

\section{Jumlah Layanan}

Sarana pengolahan sampah organik di RW 7 Kelurahan Kebon Pisang melayani sebanyak 59 jiwa, jumlah ini diperoleh berdasarkan persen reduksi sampah yang saat ini masih sebesar $(3,15 \%)$ dikali dengan jumlah total penduduk yang ada di RW 7 Kelurahan Kebon Pisang (1.856 jiwa).

\section{Kelayakan Sampah Untuk Dikomposkan}

Pada aspek ini akan dilakukan analisa karakteristik sampah organik di RW 7 Kelurahan Kebon Pisang berdasarkan dari hasil uji karakteristik yang telah dilakukan sebelumnya di laboratorium. Pengujian ini dilakukan dengan beberapa metode dan akan menghasilkan data-data, diantaranya data kadar air sampah, kadar volatil sampah, kadar nitrogen sampah, kadar karbon organik, dan rasio $\mathrm{C} / \mathrm{N}$ sampah.

Sampel yang diambil untuk pengujian karakteristik sampah organik ini dilakukan pada dua hari weekday dan satu hari weekend. Pada hari weekday pertama, diambil sampel sampah organik seberat 300 gram, sedangkan hari weekday kedua dan hari weekend diambil seberat 200 gram.

\begin{tabular}{|c|c|c|c|c|}
\hline Parameter & Hari 1 & Hari 2 & Hari 3 & $\begin{array}{c}\text { Rata- } \\
\text { rata }\end{array}$ \\
\hline Kadar Air & 28,2 & 75.04 & 27,1 & 43,44 \\
\hline $\mathrm{N}_{2}$ & 1,15 & 1,69 & 1,07 & 1,30 \\
\hline $\mathrm{C} . \mathrm{O}$ & 47,04 & 41,08 & 47,11 & 45,07 \\
\hline
\end{tabular}


Jurnal SEOI - Fakultas Teknik Universitas Sahid Jakarta

Vol 2 edisi 2 tahun 2020

Hasil perhitungan rasio $\mathrm{C} / \mathrm{N}$ berdasarkan hasil uji karakteristik karbon dan nitrogen adalah sebagai berikut:

$=\underline{\% \text { karbon organic sampah }}$

$\%$ nitrogen sampah

$=45.07 \% / 1.30 \%$

$=34,66$

Kondisi Ideal Pengolahan Sampah Berdasarkan Perencanaan dan Kriteria Desain Perhitungan Kebutuhan Sarana

1. Bata Terawang

\begin{tabular}{ccccc}
\hline No & Jenis Data & Sumber Data & Hasil & Satuan \\
\hline 1 & Persentase sampah masuk & $\begin{array}{c}\text { Sekunder } \\
(\mathrm{PS})\end{array}$ & 26 & $\%$ \\
\hline 2 & Dimensi & $\begin{array}{c}\text { Sekunder } \\
(\mathrm{PS})\end{array}$ & $\begin{array}{c}0,75 \times 0,64 \mathrm{x} \\
1,23\end{array}$ & $\mathrm{~m}$ \\
\hline 4 & Kapasitas & $\begin{array}{c}\text { Sekunder } \\
(\mathrm{KD})\end{array}$ & 0,59 & $\mathrm{~m}^{3}$ \\
\hline 5 & Vol. Timbunan kompos & $\begin{array}{c}\text { Sekunder } \\
(\mathrm{KD})\end{array}$ & 0,44 & $\mathrm{~m}^{3}$ \\
\hline 6 & Lama Pengomposan & $\begin{array}{c}\text { Sekunder } \\
(\mathrm{PS})\end{array}$ & 30 & $\mathrm{hari}$ \\
\hline 7 & $\begin{array}{c}\text { Volume sampah berdasarkan } \\
\text { sampah yang akan masuk }\end{array}$ & $\begin{array}{c}\text { Sekunder } \\
(\mathrm{KD})\end{array}$ & 0,84 & $\mathrm{~m}^{3} / \mathrm{hari}$ \\
\hline
\end{tabular}

\section{Contoh Perhitungan}

\section{Total Volume Pengomposan}

$=$ lama pengomposan $\mathrm{x}$ volume sampah yang akan masuk

$=30$ hari $\mathrm{x} 0,22 \mathrm{~m}^{3} /$ hari $=6,6 \mathrm{~m}^{3}$

\section{Jumlah Unit Dibutuhkan}

$=$ total vol pengomposan / vol timbunan kompos

$=6.6 \mathrm{~m} 3=15$ unit

$0,44 \mathrm{~m}$

2. Drum Komposter

\begin{tabular}{ccccc}
\hline No & Jenis Data & Sumber Data & Hasil & Satuan \\
\hline 1 & Persentase sampah masuk & Sekunder (PS) & 34 & $\%$ \\
\hline 2 & Dimensi & Sekunder (PS) & $0,75 \times 1,3$ & $\mathrm{~m}$ \\
\hline 3 & Kapasitas & Sekunder (KD) & 0,58 & $\mathrm{~m}^{3}$ \\
\hline 4 & Vol. Timbunan kompos & Sekunder (KD) & 0,44 & $\mathrm{~m}^{3}$ \\
\hline 6 & Lama Pengomposan & Sekunder (PS) & 30 & hari \\
\hline 7 & Volume sampah per hari & Sekunder (KD) & 0,84 & $\mathrm{~m}^{3} / \mathrm{hari}$ \\
\hline
\end{tabular}

\section{Contoh Perhitungan}

\section{Total Volume Pengomposan}

= lama pengomposan $\mathrm{x}$ volume sampah yang akan masuk

$=30$ hari $\times 0,29 \mathrm{~m}^{3} /$ hari

$=8,7 \mathrm{~m}^{3}$ 
Jurnal SEOI - Fakultas Teknik Universitas Sahid Jakarta

Vol 2 edisi 2 tahun 2020

$$
\begin{aligned}
& \frac{\text { Jumlah Unit Dibutuhkan }}{=\frac{\text { total vol pengomposan } \mathrm{m} 3}{\text { Vol timbunan kompos } \mathrm{m} 3}} \\
& =8.7 \mathrm{~m} 3 / 0.44 \mathrm{~m} 3=19 \text { unit }
\end{aligned}
$$

3. Biodigester

\begin{tabular}{ccccc}
\hline No & Jenis Data & Sumber Data & Hasil & Satuan \\
\hline 1 & Persentase sampah masuk & Sekunder (PS) & 40 & $\%$ \\
\hline 2 & Dimensi & Sekunder (PS) & $1,6 \times 0,86 \times 0,8$ & $\mathrm{~m}$ \\
\hline 3 & Kapasitas & Sekunder (KD) & 1,150 & $\mathrm{~m}^{3}$ \\
\hline 4 & Vol. Timbunan kompos & Sekunder (KD) & 1,150 & $\mathrm{~m}^{3}$ \\
\hline 5 & Lama Pengomposan & Sekunder (PS) & 30 & hari \\
\hline 6 & Volume sampah per hari & Sekunder (KD) & 0,84 & $\mathrm{~m}^{3} / \mathrm{hari}$ \\
\hline 7 & $\begin{array}{c}\text { Volume sampah berdasarkan } \\
\text { sampah yang akan masuk }\end{array}$ & Sekunder (KD) & 0,34 & $\mathrm{~m}^{3} / \mathrm{hari}$ \\
\hline
\end{tabular}

Contoh Perhitungan

\section{Total Volume Pengomposan}

= lama pengomposan $\mathrm{x}$ volume sampah yang akan masuk

$=30$ hari $\times 0,34 \mathrm{~m}^{3} /$ hari

$=10,2 \mathrm{~m}^{3}$

\section{Jumlah Unit Dibutuhkan}

$=\underline{\text { total vol pengoposan } \mathrm{m} 3}$

Vol timbunan kompos $\mathrm{m} 3$

$=10.2 \mathrm{~m} 3 / 1,15 \mathrm{~m} 3=9$ unit

Tabel 2 Rekapitulasi Jumlah Sarana dalam Kondisi Ideal

\begin{tabular}{ccc}
\hline No & Sarana & $\begin{array}{c}\text { Jumlah Unit Yang } \\
\text { Dibutuhkan }\end{array}$ \\
\hline 1 & Bata Terawang & 15 Unit \\
2 & Drum Komposter & 19 Unit \\
3 & Biodigester & 9 Unit \\
\hline & Jumlah Sarana & 43 Unit \\
\hline
\end{tabular}

Tabel 3 Rekapitulasi Kebutuhan Total Lahan

\begin{tabular}{ccc}
\hline No & Sarana & $\begin{array}{c}\text { Kebutuhan Total } \\
\text { Lahan }\end{array}$ \\
\hline 1 & Bata Terawang & $18,11 \mathrm{~m}^{2}$ \\
2 & Drum Komposter & $14,25 \mathrm{~m}^{2}$ \\
3 & Biodigester & $27,52 \mathrm{~m}^{2}$ \\
\hline & Total Lahan & $59,88 \mathrm{~m}^{2}$ \\
\hline
\end{tabular}

\section{Kesimpulan Hasil Analisa Perbandingan Kondisi Eksisting dan Ideal}

Berdasarkan hasil analisa perbandingan kondisi eksisting dan kondisi ideal, jumlah sarana pengolahan yang perlu digunakan untuk mencapai kondisi ideal yaitu dengan menambahkan unit sarana bata terawang 13 unit, drum komposter ditambah 15 unit, biodigester ditambah 8 unit. Penambahan jumlah unit tersebut berdampak pada peningkatan pemanfaatan lahan. Pada kondisi 
eksisting lahan efektif yang digunakan sebesar $39,85 \mathrm{~m}^{2}$, sedangkan pada kondisi ideal pemanfaatan lahan menjadi $59,88 \mathrm{~m}^{2}$. Penggunaan tiga jenis sarana menyebabkan ruang gerak menjadi sangat terbatas karena ukuran biodigester yang besar dan sulit diposisikan apabila lebih dari dua unit, hal ini membuat sarana biodigester harus dieliminasi dan mengalihkan pemanfaatan kepada sarana bata terawang dan drum komposter. Target reduksi sampah sebesar 30\% pada tahun 2025 juga dapat dicapai dengan peningkatan reduksi sebesar 6,71\% per tahun. Perbandingan jumlah layanan antara kondisi eksisting dan kondisi ideal cukup jauh, karena jumlah layanan pada kondisi eksisting masih hanya $3,15 \%$ sedangkan untuk kondisi idealnya $30 \%$. Pada pengomposan dimasa yang akan datang, dapat dilakukan penambahan air pada sampah organik dan penambahan kotoran hewan untuk menyeimbangkan rasio $\mathrm{C} / \mathrm{N}$ sampah.

\section{Proyeksi Jumlah Penduduk dan Timbulan Sampah Tahun 2020-2025}

Tabel 4 Rekapitulasi Proyeksi Jumlah Penduduk RW 7 Th. 2022-2025

\begin{tabular}{ccc}
\hline No & Tahun & Jumlah Penduduk \\
\hline 1 & 2022 & 1782 \\
2 & 2023 & 1798 \\
3 & 2024 & 1814 \\
4 & 2025 & 1830 \\
\hline
\end{tabular}

Tabel 5 Hasil Proyeksi Satuan Timbulan Sampah Th. 2021- 2025

\begin{tabular}{ccc}
\hline No & Tahun & $\begin{array}{c}\text { Satuan Timbulan } \\
\text { Sampah (Kg/orang/hari) }\end{array}$ \\
\hline 1 & 2021 & 0,45 \\
2 & 2022 & 0,46 \\
3 & 2023 & 0,46 \\
4 & 2024 & 0,47 \\
5 & 2025 & 0,47 \\
\hline
\end{tabular}

Tabel 6 Hasil Proyeksi Total Timbulan Sampah Th. 2021-2025

\begin{tabular}{cccc}
\hline No & Tahun & $\begin{array}{c}\text { Total Timbulan } \\
\text { Sampah (Kg/hari) }\end{array}$ & $\begin{array}{c}\text { Timbulan Sampah } \\
\text { Organik (Kg/hari) }\end{array}$ \\
\hline 1 & 2021 & 835,2 & 429,7 \\
2 & 2022 & 819,7 & 421,7 \\
3 & 2023 & 827,1 & 425,5 \\
4 & 2024 & 852,6 & 438,6 \\
5 & 2025 & 860,1 & 442,5 \\
\hline
\end{tabular}

\section{Alternatif Optimalisasi Sarana Pengolahan Sampah Organik}

- Unit pengolahan tunggal atau single treatment unit Alternatif unit pengolahan tunggal (single treatment unit) adalah proses pengolahan yang hanya akan menggunakan satu jenis sarana pengolahan yang dipilih dari tiga jenis sarana yang direncanakan, yaitu bata terawang, drum komposter, dan biodigester.

- Unit pengolahan kombinasi atau multiple treatment unit 
Jurnal SEOI - Fakultas Teknik Universitas Sahid Jakarta

Vol 2 edisi 2 tahun 2020

Alternatif unit pengolahan kombinasi (multiple treatment unit) adalah proses pengolahan sampah yang menerapkan sarana pengolahan kombinasi atau campur dari sarana-sarana terpilih. Alternatif-alternatif ini diperoleh berdasarkan hasil analisa perbandingan kondisi eksisting dan kondisi ideal. Sarana biodigester harus dieliminasi dari perencanaan karena sulit diposisikan di lahan eksisting. Penyisihan biodigester juga dilakukan karena tidak cukupnya lahan dan menimbang kondisi eksisting, biodigester tidak berfungsi dan kurang diminati. Berdasarkan analisa tersebut juga diperoleh hasil bahwa target reduksi sampah $30 \%$ dapat dicapai dengan kenaikan $6,71 \%$ per tahun.

\section{Alternatif 1}

\begin{tabular}{ccccc}
\hline Tahun & $\begin{array}{c}\text { Jumlah } \\
(\text { Unit })\end{array}$ & $\begin{array}{c}\text { Luas Lahan } \\
\left(\mathrm{m}^{2}\right)\end{array}$ & $\begin{array}{c}\text { Reduksi } \\
\text { Sampah } \\
(\%)\end{array}$ & $\begin{array}{c}\text { Jumlah } \\
\text { Layanan } \\
(\text { Jiwa })\end{array}$ \\
\hline \multicolumn{5}{c}{ Bata Terawang } \\
\hline 2021 & 14 & 16,94 & $3,15 \%$ & 59 \\
2022 & 26 & 31,46 & $9,86 \%$ & 176 \\
2023 & 38 & 45,98 & $16,57 \%$ & 298 \\
2025 & 49 & 59,29 & $23,29 \%$ & 423 \\
\hline \multicolumn{5}{c}{ Drum Komposter } \\
\hline 2021 & 11 & 8,25 & $3,15 \%$ & 549 \\
2022 & 19 & 14,25 & $9,86 \%$ & 59 \\
2023 & 28 & 21 & $16,57 \%$ & 298 \\
2024 & 37 & 27,75 & $23,29 \%$ & 423 \\
2025 & 47 & 35,25 & $30 \%$ & 549 \\
\hline
\end{tabular}

Sarana bata terawang dari tahun 2021 hingga tahun 2025 membutuhkan total 61 unit untuk mengolah seluruh sampah organik di RW 7 Kelurahan Kebon Pisang dengan luas lahan yang dibutuhkan mencapai $73,81 \mathrm{~m}^{2}$ pada tahun 2025 atau jika ingin menggunakan sarana drum komposter saja hanya membutuhkan 47 unit pada tahun 2025. Dari aspek pemanfaatan lahan, luas lahan yang dibutuhkan agar dapat mengimplementasikan sarana drum komposter hanya mencapai $35,25 \mathrm{~m}^{2}$ pada tahun 2025 .

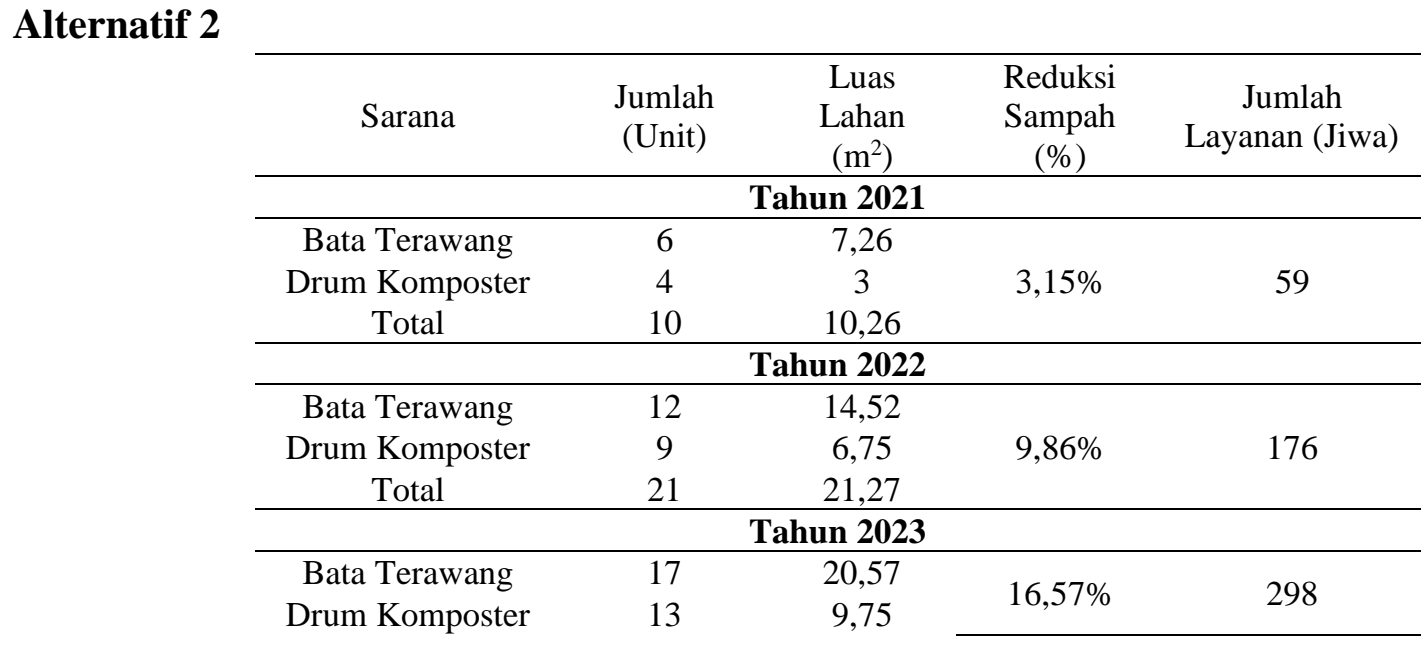


Jurnal SEOI - Fakultas Teknik Universitas Sahid Jakarta

Vol 2 edisi 2 tahun 2020

\begin{tabular}{|c|c|c|c|c|}
\hline Total & 30 & 30,32 & & \\
\hline \multicolumn{5}{|c|}{ Tahun 2024} \\
\hline Bata Terawang & 23 & 27,83 & & \\
\hline Drum Komposter & 18 & 13,5 & $23,29 \%$ & 423 \\
\hline Total & 41 & 41,33 & & \\
\hline \multicolumn{5}{|c|}{ Tahun 2025} \\
\hline Bata Terawang & 29 & 35,09 & & \\
\hline Drum Komposter & 22 & 16,5 & $30 \%$ & 549 \\
\hline Total & 51 & 51,59 & & \\
\hline
\end{tabular}

Sarana bata terawang mendapatkan persentase sebesar 50\% sampah organik, maka dibutuhkan sebanyak 29 unit pengolahan pada tahun 2025 yang akan membutuhkan luas lahan sebesar 35,09 $\mathrm{m}^{2}$. Sedangkan sarana drum komposter membutuhkan 22 unit pada tahun 2025 untuk mengolah $50 \%$ sampah organik, untuk luas lahan yang dibutuhkan yaitu sebesar $16,5 \mathrm{~m}^{2}$, maka total luas lahan yang dibutuhkan yaitu sebesar $51,59 \mathrm{~m}^{2}$.

\section{Biaya Perawatan}

Tabel 7 Biaya Perawatan Sarana Pengolahan Alternatif 1

\begin{tabular}{ccccc}
\hline Sarana & Biaya/unit & $\begin{array}{c}\text { Jumlah } \\
\text { Unit }\end{array}$ & Per Tahun & Per Bulan \\
\hline Bata Terawang & Rp. 200.000 & 61 & Rp. 12.200.000 & Rp. 1.016.000 \\
\hline Drum Komposter & Rp. 200.000 & 47 & Rp. 9.400.000 & Rp. 783.500 \\
\hline
\end{tabular}

Tabel 8 Biaya Perawatan Sarana Pengolahan Alternatif 2

\begin{tabular}{ccccc}
\hline Sarana & Biaya/unit & Jumlah Unit & Per Tahun & Per Bulan \\
\hline Bata Terawang & Rp. 200.000 & 29 & Rp. 5.800.000 & Rp. 483.500 \\
\hline Drum Komposter & Rp. 200.000 & 22 & Rp. 4.400.000 & Rp. 366.500 \\
\hline & Total & & Rp. 10.200 .000 & Rp. 850.000 \\
\hline
\end{tabular}

Berdasarkan analisa data pemilihan alternatif di atas, dapat disimpulkan bahwa sarana drum komposter pada alternatif 1 (unit pengolahan tunggal) terpilih menjadi alternatif optimalisasi sarana pengolahan sampah organik RW 7 Kelurahan Kebon Pisang. Karena sarana drum komposter merupakan sarana dengan penggunaan lahan paling kecil, perawatan dan pengoperasian yang mudah, dan biaya perawatan yang paling murah apabila dibandingkan dengan alternatif-alternatif yang lainnya

\section{Kesimpulan}

Target reduksi sampah di RW 7 pada tahun 2025 yaitu sebesar 30\%, namun pada saat ini masih hanya mereduksi sampah sebesar 3,15\%. Untuk mencapai target tersebut perlu dilakukan kenaikan reduksi sampah setiap tahunnya, dari hasil perhitungan dapat disimpulkan bahwa harus ada kenaikan sebesar $6,71 \%$ per tahun sampai tahun 2025. Reduksi sampah $30 \%$ pada tahun 2025 dapat diperoleh dengan menggunakan alternatif optimalisasi sarana pengolahan terpilih yakni Alternatif 1 (unit pengolahan tunggal) dengan sarana Drum Komposter sebanyak 47 unit sarana. Alternatif terpilih ditentukan berdasarkan aspek-aspek yang sudah ditentukan, seperti aspek lahan, aspek reduksi sampah, aspek kemudahan dalam pengoperasiannya, aspek ekonomis. 
Jurnal SEOI - Fakultas Teknik Universitas Sahid Jakarta

Vol 2 edisi 2 tahun 2020

\section{Daftar Pustaka}

Damanhuri, E. 2010. pengelolaan Sampah. Bandung: ITB Press.

Kurnia, V. C. 2017. Pengaruh Kadar Air Terhadap Hasil Pengomposan Sampah Organik dengan Metode Open Windrow. Jurnal Teknik Mesin, 61.

Mirwan, M. 2015. Optimasi Pengomposan Sampah Kebun dengan Variasi Aerasi dan Penambahan Kotoran Sapi sebagai Bioaktivator. Jurnal Teknik Kimia.

Satori, M. 2018. Pengolahan Sampah Organik Rumah Tangga dengan Metode Bata Terawang. Jurnal Teknik Lingkungan.

Setyorini, D. 2006. Kompos. Pupuk Organik dan Hayati, 19.

Subandriyo. 2012. Optimasi Pengomposan Sampah Organik Rumah Tangga Menggunakan Kombinasi Aktivator EM4 dan MOL Terhadap Rasio C/N Jurnal Teknik Kimia.

Sulistyorini, L. 2005. Pengelolaan Sampah Dengan Cara Menjadikannya Kompos. Jurnal Kesehatan Lingkungan, 77.

Wahyono, S. 2001. Pengolahan Sampah Organik dan Aspek Sanitasi. Jurnal Teknologi Lingkungan.

Zumrodi. 2017. Teknik Pengomposan Sampah Organik. Bandung

Djulianti, Y. 2019. Identifikasi Program Kawasan Bebas Sampah Kota Bandung. Bandung: Itenas.

Djulianti, Y. 2019. Identifikasi Tingkat Pengurangan Sampah Dengan Adanya Program Kawasan Bebas Sampah. Jurnal Teknik Lingkungan.

Afifah, N. H. 2018. Studi Komparasi Komposter Berbasis Masyarakat. Jurnal Teknik Lingkungan. Arikunto. 2002. Prosedur Penelitian. Jakarta: Rineka Cipta.

Bandung, D. L. 2015. Panduan Teknis Kawasan Bebas Sampah. Bandung.

Hartati. 2020. Metode Geometri, Metode Artimatika, dan Metode Eksponensial untuk Memproyeksikan Penduduk Provinsi Sumatera Selatan. Prosiding Seminar Nasional Sains Matematika Informatika dan Aplikasinya IV, 8-9.

Luo, W dan Chen, T.B. 2007. Effect of moisture adjustments on vertical temperature distribution during force-aeration static-pile composting of sewage sludge. Science Direct 